\title{
Patrimônio Mineiro e valorização dos testemunhos da mineração pretérita: resquícios existentes na Serra do Lenheiro, São João del-Rei, Minas Gerais, Brasil
}

\author{
Mining Heritage and valorisation of the past mining evidence: remnants in the Lenheiro \\ Ridge, São João del-Rei, Minas Gerais State, Brazil
}

Múcio do Amaral Figueiredo Geógrafo, Professor Doutor, UFSJ muciofigueiredo@ufsj.edu.br

\author{
Arlon Cândido Ferreira \\ Geógrafo, Doutorando em Geografia, UFF \\ arloncf@gmail.com \\ Leonardo Cristian Rocha \\ Geógrafo, Professor Doutor, UFSJ \\ rochageo@ufsj.edu.br \\ Helton Santos Lopes Barbosa \\ Geógrafo, Mestrando em Geografia, UFSJ \\ heltonbarbosa.geo@gmail.com
}

\begin{abstract}
Resumo
O patrimônio mineiro vem aparecendo como uma nova área do conhecimento, sendo considerado um desdobramento do que se conhece como geopatrimônio. Como uma ramificação científica interdisciplinar, abarca desde a patrimonialização de prédios e equipamentos da atividade minerária interrompida em décadas passadas, até a inventariação e análise de resquícios da atividade minerária de períodos proto industriais e pré-industriais (anteriores ao séc. XIX). Os conceitos apresentados, advindos de investigações e reflexões de autores de vários países, apontam para um rico ambiente de investigação, capaz de agregar e valorar importantes aspectos da construção histórico-cultural das comunidades desenvolvidas a partir da atividade mineradora. A Serra do Lenheiro e a região de São João del-Rei, em Minas Gerais, uma outrora importante cidade da região sudeste do Brasil, polarizando um vasto território em períodos coloniais da história brasileira, nasceu e se desenvolveu a partir da descoberta de ouro em suas cercanias. Os resquícios das atividades minerárias setecentistas e oitocentistas ainda se fazem presentes na paisagem da referida Serra, marcando um importante momento na história da região e da centenária cidade. Faz-se necessário, como desdobramento deste trabalho, uma futura investigação mais detalhada para que se conheça em detalhes essas construções minerárias de períodos coloniais, iniciando, assim, mais um capítulo na rica história da cidade de São João del-Rei e região.
\end{abstract}

Palavras chave: geopatrimônio, patrimônio mineiro, mineração, geoconservação.

\begin{abstract}
The mining heritage has been appearing as a new area of knowledge, being considered an unfolding of what is known as geoheritage. As an interdisciplinary scientific branch, it ranges from the patrimonialization of buildings and equipment of the mining activity interrupted in past decades, until the inventory and analysis of remnants of the mining activity of proto industrial and pre-industrial periods (before the 19th century). The concepts presented, based on research and reflections of authors from several countries, point to a vibrant research environment capable of adding and valuing essential aspects of the historical-cultural construction of communities developed from the mining
\end{abstract}


activity. The Lenheiro Ridge and the region of São João del-Rei in Minas Gerais, a once important city in southeastern Brazil, polarising a vast territory in colonial periods of Brazilian history, was born and developed from the discovery of gold in its surroundings. The remnants of the eighteenth and eighteenth-century mining activities are still present in the landscape of the Ridge, marking an essential moment in the history of the region and the centenary city. It is necessary, as a result of this work, a more detailed future investigation to know in detail these mining constructions of colonial periods, thus beginning another chapter in the rich history of the city of São João del-Rei and region.

Keywords: geoheritage, mining heritage, mining, geoconservation.

\section{INTRODUÇÃO}

Mineração e geoconservação possuem objetivos diferentes para com os elementos da geodiversidade. As atividades minerárias tomam os recursos abióticos como um bem que pode ser mensurado economicamente, passível de exploração e necessário para o desenvolvimento do homem na sociedade e seu bem-estar. Por outro lado, a geoconservação objetiva a proteção do patrimônio geológico, um requisito básico e essencial para a sua conservação, pois contém informações que contam o passado geológico da Terra (DIAS, 2015).

As questões relacionadas com a conservação do patrimônio geológico ou geoconservação são muito recentes, tendo despontado somente na década de 90 durante a conferência de Malvern no Reino Unido. A temática da geoconservação está fundamentada na elaboração e implementação de estratégias de conservação do patrimônio geológico a partir da utilização de metodologias de trabalho que visam à sistematização de ações de inventariação, avaliação, conservação, valorização, divulgação e monitoramento do patrimônio geológico de uma determinada área, seja um país, estado, unidades de conservação, entre outros (BRILHA, 2005).

A atividade extrativista mineral foi e ainda é, sem dúvidas, imprescindível ao desenvolvimento das sociedades ao longo da história. Todavia, além de fornecer matérias-primas para inúmeras atividades recorrentes, a extração mineral também é responsável por gerar o que se pode chamar de Patrimônio Mineiro (LICCARDO; BARBOSA, HORNES, 2012). O Patrimônio Mineiro está relacionado com o conteúdo material (ruínas, pedreiras, estruturas, equipamentos, etc), assim como os aspectos intangíveis (cultura, memória, miscigenação) (GUIMARÃES; LICCARDO; PIEKARZ, 2013). Neste patrimônio, o passado e o presente registram a história, a identidade e a cultura da região associada aos diferentes recursos minerais encontrados (NASCIMENTO; ROCHA; NOLASCO, 2013).

Na Europa, um extenso e consolidado conjunto de publicações investigando vestígios de mineração desde os tempos do Império Romano até à atualidade têm sido preservados e resgatados como um aspecto da memória e patrimônio cultural dos lugares, além de apresentar um significativo potencial na divulgação e conservação dos elementos da geodiversidade. A instituição governamental 
espanhola "Instituto Geológico y Minero de España" ocupa lugar de destaque na pesquisa e divulgação do patrimônio industrial ligado à mineração e à própria mineração.

Segundo Puche Riart (2000), o primeiro grupo de pesquisadores que almejava a conservação do patrimônio mineiro foi formado na região mineradora da Cornualha, no País de Gales, Reino Unido, onde, em 1935, foi criado o Cornish Enginers Preservation Commitee, voltado para a promoção e conservação dos edifícios ligados à atividade mineradora local pretérita.

Nesse sentido, a noção de preservação/conservação patrimonial suscita que o "patrimônio" pode ser entendido como as coisas ou lugares que queremos manter, aproveitar ou aprender com gerações passadas, muitos aspectos do nosso ambiente cultural, entre eles, lugares que passaram por mineração. Um "lugar" neste contexto, pode ser um sítio, área, edificação ou outro tipo de trabalho, juntamente com conteúdos associados (máquinas e demais utensílios) e seus arredores. No entanto, nosso ambiente cultural contém uma infinidade de "lugares" e nem todos são integralmente de tal valor que devamos retê-los e passá-los a gerações futuras: muitos não são considerados uma herança patrimonial (PEARSON; McGOWAN, 2000).

Uma maneira pela qual separamos lugares com valor patrimonial (ou "significado cultural") do restante é avaliar a comunidade ou grupo social. Uma ferramenta neste processo é o uso de uma série de critérios metodológicos que pode nos ajudar a identificar quaisquer valores patrimoniais que os lugares possam ter (PEARSON; McGOWAN, 2000).

O patrimônio de um lugar que passou por mineração pode ser sugerido, por exemplo, por um reconhecimento da comunidade local de sua importância, ou por um grupo particular (como a sociedade histórico-geográfica local ou os órgãos estaduais ou nacionais de gestão do patrimônio) de pesquisa da história mineira (ou da mineração), cujo papel possa ter sido fundamental na história local, regional ou estadual. Ainda é útil, no entanto, sujeitar lugares obviamente valorizados para avaliar os critérios, como o meio natural em que está inserido e decidindo se, e como, o lugar deve ser gerenciado para proteger esses valores (PEARSON; McGOWAN, 2000).

O patrimônio cultural de um dado espaço geográfico é constituído por todos aqueles elementos e manifestações tangíveis ou intangíveis produzidos pela sociedade, resultado de um processo histórico em que a reprodução das ideias e dos quesitos materiais se constitui em um fator que identifica e diferencia uma dada região de outras. Está relacionado com a herança, pois é um conceito que alude à história, se junta com a própria essência da cultura e é assumido diretamente pelos grupos sociais locais. Isso implica em um processo de reconhecimento intergeracional de alguns elementos (desde o território até uma construção ruiniforme) como parte da bagagem cultural, e sua vinculação a um sentimento de grupo (FERNÁNDEZ et al., 2015; SANTANA TALAVERA, 2003). 
O patrimônio, portanto, é o produto de um processo histórico, dinâmico, uma categoria que se vai conformando a partir da interação de distintos atores sociais e de diferentes situações, que obrigam a realizar um olhar de longo prazo, tanto na concepção como no uso dos recursos.

Desta forma, o patrimônio mineiro se estabelece dentro do patrimônio cultural e pode ser entendido como o conjunto de atividades minerárias realizadas em explorações a céu aberto ou subterrâneas, estruturas imóveis e móveis, assim como instalações periféricas, de transporte, documentos, objetos e elementos imateriais (formas de trabalho), vinculados com atividades minerárias do passado o atuais, ao qual um grupo social reconhece valores históricos, culturais ou sociais.

Este reconhecimento ocasional é minimizado ou relativizado, produto da imagem negativa que tem a atividade mineradora por suas ações, entendidas como destrutivas e perturbadoras da paisagem (FERNÁNDEZ et al., 2015).

Ainda segundo Fernández et al. (2015), o patrimônio mineiro, produto do trabalho humano com a mineração, é considerado hoje um dos componentes do patrimônio cultural que deve ser conservado e preservado por seu valor para a identidade social, assim como também pela importância que vem assumindo no potencial desenvolvimento turístico de muitas regiões, iniciado há décadas na Europa e que começa a expandir-se por todo o mundo. Entretanto, é relativamente novo o conceito de geodiversidade, entendido como contrapartida ao conceito de biodiversidade, que também começa a ser discutido e analisado em diferentes instâncias, e se observa, ao mesmo tempo, sua importância para a preservação de fenômenos e processos abióticos e suas relações com o restante dos fatores ambientais, sociais e culturais.

Em relação à geodiversidade e à biodiversidade, surge o denominado geoturismo, como uma modalidade dentro do turismo alternativo, que busca a revalorização do geopatrimônio e da geodiversidade, ao mesmo tempo que se converte em um instrumento valioso para sua conservação.

Esta simbiose do patrimônio mineiro, geodiversidade e geoturismo pode traduzir-se nos denominados parques geomineiros, os quais são áreas mais o menos extensas onde é possível resgatar e valorar resquícios da atividade mineira, de características geológicas e geomorfológicas locais, etc., contribuindo assim com a possibilidade de um desenvolvimento local dentro do marco da sustentabilidade (FERNÁNDEZ et al., 2015).

A partir da década de 1960, a história ganha uma nova especialidade a "arqueologia industrial", que envolve a memória da evolução das técnicas industriais, a cultura dos trabalhadores e a preservação das infraestruturas das indústrias, que remontam do período pré-industrial, perpassa as revoluções industriais até chegar aos dias de hoje. Com a crescente pesquisa nessa área, é criada o The International Committee for the Conservations of the Industrial Heritage (TICCIH), voltado para a proteção do patrimônio industrial (DIAS, 2015). 
Com a publicação da Carta de Nazhny Tagil sobre o Patrimônio Industrial, em 2003, foram definidos os conceitos de arqueologia Industrial e Patrimônio Industrial, adotados pela UNESCO nos seguintes termos:

O patrimônio industrial compreende os vestígios da cultural industrial que possuem valor histórico, tecnológico, social, arquitetônico ou científico. Estes vestígios englobam edifícios e maquinários, oficinas, fábricas, minas e locais de processamento e de refinação, entrepostos e armazéns, centros de produção [...], assim como locais onde se desenvolveram atividades sociais relacionadas com a indústria, tais como habitações, locais de couto ou de educação. A arqueologia industrial é um método interdisciplinar que estuda todos os vestígios, materiais imateriais, os documentos, os artefatos, a estratigrafia e as estruturas, as implantações humanas e as paisagens naturais e urbanas, criadas para ou por processos industriais (TICCIH, 2003, p. 3).

Sendo que o conceito de Patrimônio Industrial diz respeito as atividades industriais como um todo e o conceito de arqueologia industrial ocupa-se da investigação metódica dos vestígios patrimoniais da indústria.

Dias (2015) considera que o conceito anterior resultou na formação do conceito de patrimônio mineiro, que por sua vez, vem trazer especificidade à indústria de exploração mineral, envolvendo todo o legado histórico, cultural e material ligado diretamente à mineração, caracterizando um ramo do patrimônio industrial especificamente ligada à exploração minerária. Sendo assim, ainda segundo Dias (2015) a distinção entre patrimônio industrial e patrimônio mineiro não é tão fácil, optando pela interconexão entre os dois conceitos, sendo este último contido no primeiro, ou a mineração um dos ramos industriais (DIAS, 2015). A conexão com a geodiversidade se dá pelo fato da cultura e os costumes dos mineiros estarem ligados com a sua relação com as rochas e as paisagens do entorno das minas (NASCIMENTO; ROCHA; NOLASCO, 2013).

Para alguns autores o patrimônio mineiro é paralelo ao patrimônio geológico. Brilha (2005) afirma que o "patrimônio geológico não integra o que é designado por patrimônio mineiro", ainda que muitas das antigas estruturas possam ser consideradas geossítios e capazes de serem protegidas por sua finalidade pedagógica, seus valores históricos ou turísticos. Já García-Cortés (2008) envolve patrimônio mineiro como uma categoria na definição de patrimônio geológico), ressalta que o patrimônio mineiro está ligado intimamente ligado ao geológico e, para este autor, patrimônio minério dá-se com o encontro dos elementos da geodiversidade em um espaço territorial compreendido por atividades minerárias. Para del Campo et al. (2012), o patrimônio mineiro possui inegável conexão com o geológico, pois se desenvolve a partir das jazidas minerais, se conectando também com o patrimônio histórico, arqueológico e industrial.

Em consonância com tal discussão, muitos países da Europa, América Latina e também a Austrália já reconhecem a importância de proteger e divulgar a existência do patrimônio mineiro em seus territórios. Alguns países europeus apresentam uma importante base conceitual e de trabalhos 
que envolvem a preservação do patrimônio mineiro - Irlanda, Espanha, França, Itália ente outros. A Eurogeosurveys, uma associação de 33 serviços geológicos de países europeus, apresenta como um dos objetivos a preservação do patrimônio mineiro como parte fundamental da história e evolução cultural do continente, assim como a preservação das instalações e divulgação sobre o conhecimento e herança da exploração mineral e geológica, alcançada por atividades capazes de contribuir para o turismo e desenvolvimento econômico (MARCHAN; SÁNCHEZ, 2013). A Europa também abriga uma rede de cooperação e intercâmbio de informação sobre o assunto, a Euromines, atuando quanto à recuperação do patrimônio mineiro e como ele pode vir a desenvolver uma determinada região (EUROMINES, 2013).

Segundo del Campo et al. (2012), ...o patrimônio mineiro é constituído por estruturas imóveis, objetos móveis, documentos e elementos imateriais ou intangíveis, vinculados com atividades mineiras do passado, para qual um grupo social, mais ou menos amplo, atribui valores históricos, culturais ou sociais. Definição está que pode estabelecer relações tanto com o patrimônio histórico, arqueológico e industrial, como com a historia econômica, social e da tecnologia (DEL CAMPO et al., 2012, p. 8, tradução dos autores).

Del Campo et al. (2012) fazem ainda distinção entre Patrimônio Mineiro HistóricoArqueológico e Patrimônio Industrial Mineiro. O primeiro, segundo os autores, diz respeito a vestígios de atividades de mineração desenvolvidos nos tempos protoindustrial e pré-industrial, isto é, antes da primeira revolução industrial (século XVIII). O segundo, diz respeito aos restos de operações de mineração desenvolvidas a partir de meados do século XVIII, ou seja, a partir da primeira revolução industrial, com os primórdios da mecanização, até o último terço do século XX ou quando começa a ser substituído total ou parcialmente por outros sistemas envolvendo automação.

\section{A MINERAÇÃO PRETÉRITA NA SERRA DO LENHEIRO}

A Serra do Lenheiro (Fig.1) foi cenário importante na conquista e povoamento de Minas Gerais, pois por ela passava o antigo Caminho Geral do Sertão, posteriormente conhecido por Estrada Real (Caminho Velho), por onde transitou, por exemplo, o Bandeirante Fernão Dias e sua histórica “Bandeira das Esmeraldas” (FERREIRA, 2017), além de Borba Gato, Matias Cardoso e Tomé Portes del-Rei, fundador da cidade de São João del-Rei.

Segundo Ferreira (2017), a Serra do Lenheiro sempre recebeu referências na literatura técnico-geológica de Minas Gerais, devido ao histórico interesse econômico pelo ouro. De acordo com o mesmo autor, citações referentes à Serra do Lenheiro remontam a W. L. von, quando o eminente naturalista escreveu na sua conhecida obra Pluto Brasiliensis (ESCHWEGE, 2011, p. 411) sobre a questão aurífera local: “essa formação montanhosa é denominada geralmente Serra de São 
João del Rei, mas recebe denominações particulares, como por exemplo para o norte ela se chama Morro do Gambá, justamente onde havia as lavras mais importantes; para este recebe o nome de Serra de Samambaia, ao pé de Água Geral até a Lavra da Barra Vermelha”.

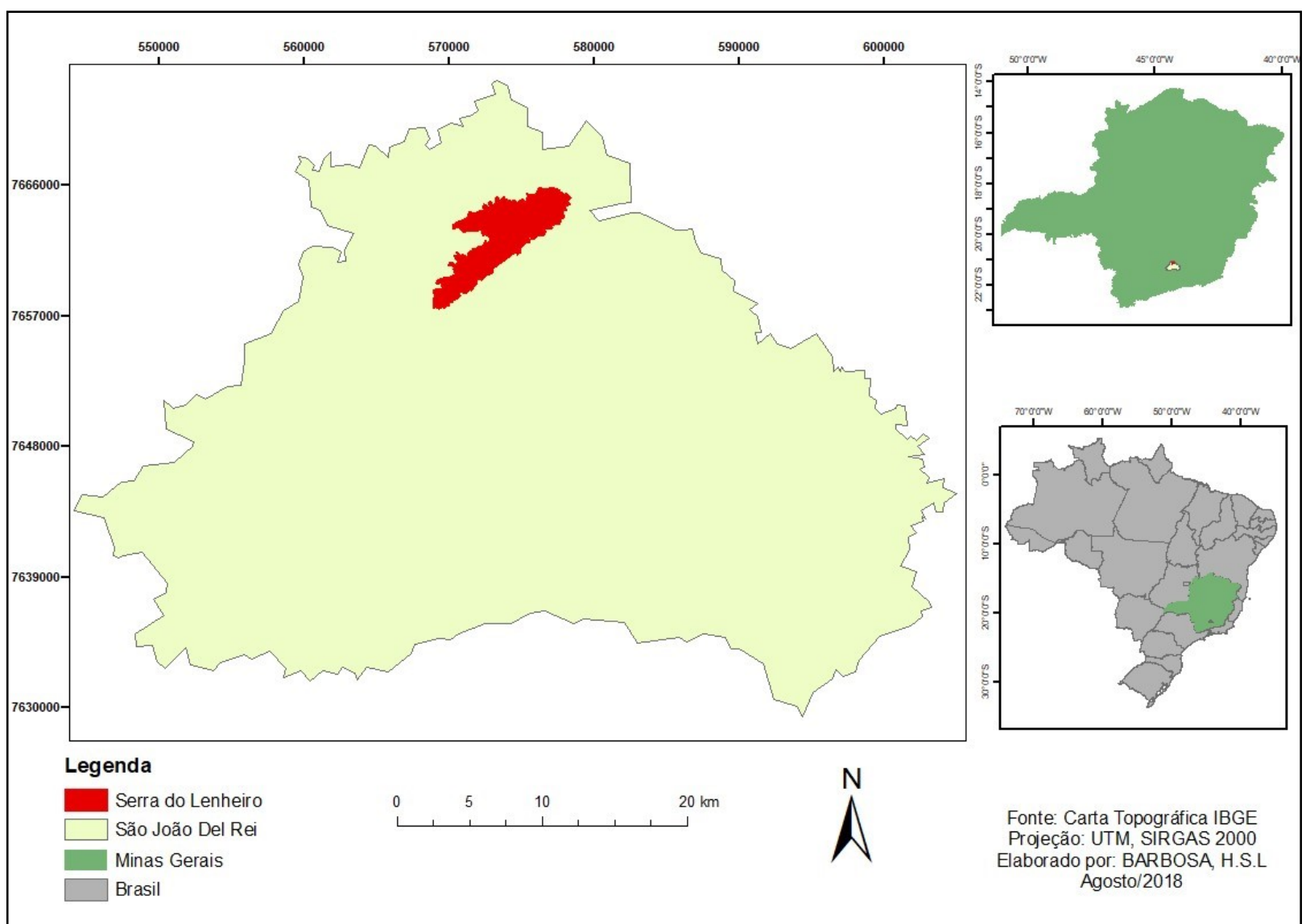

Figura 1 - Localização área da Serra do Lenheiro.

Eschwege menciona novamente a Serra do Lenheiro, quando fala que... "no morro de São João, próximo a São João del-Rei, existiam, outrora, importantes lavras. O morro é constituído de itacolomito, cujas camadas são quase verticais e possuem direção na $4^{\circ}$ hora. A formação, nesse morro, foi cortada por numerosos stringers com muita pirita arsenical [...]" (ESCHWEGE, 2011, p. 441).

Além do ouro extraído, a Serra do Lenheiro e seu entorno foram locais de extração de outros materiais utilizados nas construções das igrejas, casas, e posteriormente calçamento de ruas da cidade (MORANDI; SCHIAVONI; MIRANDA, 2018). Segundo Gaio Sobrinho (2001, p. 121):

pedra em graníticos blocos destinada à construção de nossas igrejas e pontes coloniais, escavados no local denominado Corgo Seco, no vale por detrás dos morros das Mercês e Senhor dos Montes. Também nas vizinhanças da igreja do Carmo, nas imediações do local igualmente denominado tanque, e na região do betume, no tijuco, foi retirada grande quantidade de pedra quartzito para as escadarias das Mercês e Portões do adro de São Francisco. 
Já no século XX, muito além do caráter geral das observações realizadas por Eschwege, os primeiros trabalhos mais refinados sobre o ouro da Serra do Lenheiro e região foram publicados por Lombard (1894a; 1894b), descrevendo a contemporaneidade entre as formações da Serra do Lenheiro e da vizinha Serra de São José (Tiradentes e Prados). Outros trabalhos relevantes que contribuíram para o conhecimento da estratigrafia e das estruturas do Grupo São João del-Rei surgiram à luz de trabalhos desenvolvidos em áreas

Nos primórdios de sua fundação, a cidade de São João del-Rei foi diretamente associada à mineração de ouro. No início, pela atividade garimpeira, nos talvegues dos vales da Serra do Lenheiro, devido às primitivas técnicas e da limitada mão de obra disponível. Mais tarde, da segunda metade do séc. XVIII, até o século XX, através do emprego de técnicas rudimentares, com utilização maciça de mão de obra escrava, e, a partir de meados do séc. XIX, até o séc. XX, da escavação de túneis.

A Serra do Lenheiro é geologicamente constituída por sequências metassedimentares de idade proterozóica, e, segundo Ribeiro et al. (2003) tem sido estudada desde a década de 1920. Entretanto, registros bibliográficos mais antigos, uma publicação das décadas de 30 e de 90 do séc. XIX (Pluto Brasiliensis, livro publicado pela primeira vez em1833, de autoria de W.L.v. Eschwege) e artigos publicados no periódico "Revista Industrial de Minas Geraes" (LOMBARD, 1894a e 1894b), mostram que a Serra do Lenheiro e sua vizinha Serra de São José já haviam sido geologicamente estudadas, por conta da sua potencialidade aurífera. Além disso, estudos pioneiros, sobre a estratigrafia da região de São João del-Rei, foram realizados entre as décadas de 1920 e 1950 , no qual, puderam-se observar diversas formulações da coluna estratigráfica regional (RIBEIRO et al., 2003).

$\mathrm{Na}$ atualidade, a geologia da Serra do Lenheiro (Fig. 2) apresenta uma estratigrafia onde predomina a denominada Megassequência São João del-Rei, constituída por rochas das Sequências Tiradentes, São José, Tejuco e Lenheiro, conforme detalhado em Ribeiro et al. (2003).

Nas rochas quartzíticas locais, os veios de quartzo possuem mergulho subvertical e direção N-S (VALERIANO, 1985; RIBEIRO et al. 2003). Dentre os minerais que ocorrem associados aos veios de quartzo destaca-se o ouro, cuja descoberta na Serra do Lenheiro ocasionou a fundação do aglomerado humano que resultaria na cidade de São João del-Rei. De acordo com Ribeiro et al. (2003, p.591):

o ouro nas serras do Lenheiro e São José se concentra em veios de quartzo encaixados em fácies heterolíticas no topo da Seqüência Tejuco (unidade Psjr $_{3}$ ), e em arenitos grossos seixosos no topo da Seqüência Lenheiro (unidade Psjir ). A mineralização é mais potente quando estas fácies estão em contato com diques máficos. No primeiro caso existem evidências de extração direta 
da fácies heterolítica, especialmente nos recobrimentos pelíticos, onde o ouro associa-se a pirita [...]. Já o ouro detrítico nos arenitos seixosos da unidade Psjr $_{6}$ indica que o metal foi tracionado desde a fonte no embasamento para a bacia deposicional. Depois de hospedado nas rochas das seqüências proterozóicas o ouro se concentrou em dois tipos de veios: pobres em sulfetos, encaixados nos arenitos seixosos fluviais, e veios com freqüente pirita associados a fácies heterolítica lagunar. A presença dos diques máficos parece ser mais um fator coadjuvante do que essencial na concentração do ouro.

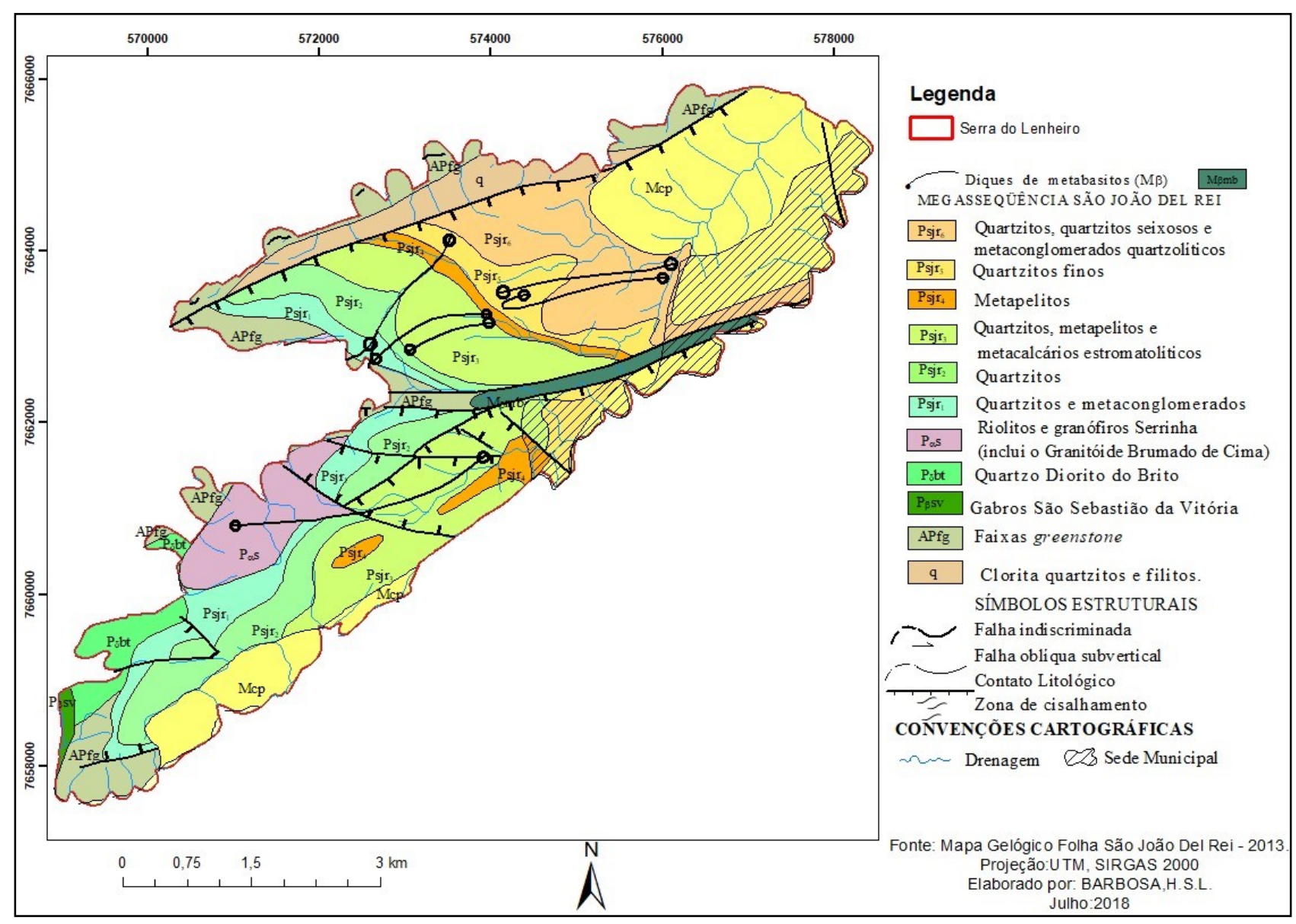

Figura 2 - Geologia da área da Serra do Lenheiro.

Neste contexto geológico e histórico, o ouro foi o principal recurso mineral explorado na Serra do Lenheiro, cuja fase áurea foi nos séculos XVIII e XIX, cujo conjunto patrimonial pode ser classificado como "Patrimônio Mineiro Histórico-Arqueológico" (del CAMPO et al., 2012), pois, mesmo estando situado temporalmente nos séculos acima citados, as técnicas utilizadas e o momento histórico do Brasil não permitem classificá-lo como "Patrimônio Industrial Mineiro", pois o país ainda não tinha passado naquele momento pela denominada Revolução Industrial, da qual a Europa, e a Espanha especificamente, pátria dos autores citados, passaram. Os vestígios de atividades de mineração desenvolvidos na Serra do Lenheiro, aqui descritos, são de tempos protoindustriais e préindustriais vigentes no Brasil colonial setecentista e oitocentista. 


\section{RESQUÍCIOS DO PATRIMÔNIO MINEIRO NA SERRA DO LENHEIRO}

Para que a produção de ouro fosse potencializada, diversas obras de engenharia foram necessárias, visando obter máximo aproveitamento do material escavado, cujo beneficiamento e apuração necessitava da disponibilização de muita água. Para isso, foram construídas barragens artificiais a montante (Fig.3), escavados canais (o principal foi o Canal dos Ingleses) que traziam água por gravidade de nascentes (Fig. 4) até os locais onde os detritos rochosos ricos em ouro retirados das escavações subterrâneas - túneis localmente conhecidos como Bêtas (Fig. 5), e dispostos para o beneficiamento em baixios escavados no terreno barrados a jusante por muros de pedras justapostas ou de terra impermeabilizados com argila, os denominados Mundéus (Fig.6). Outra forma de explotar os detritos rochosos ricos em ouro, era através de cortes que buscavam os planos de fraturas da rocha quartzítica, também localmente denominados de Grupiaras (Fig. 7).

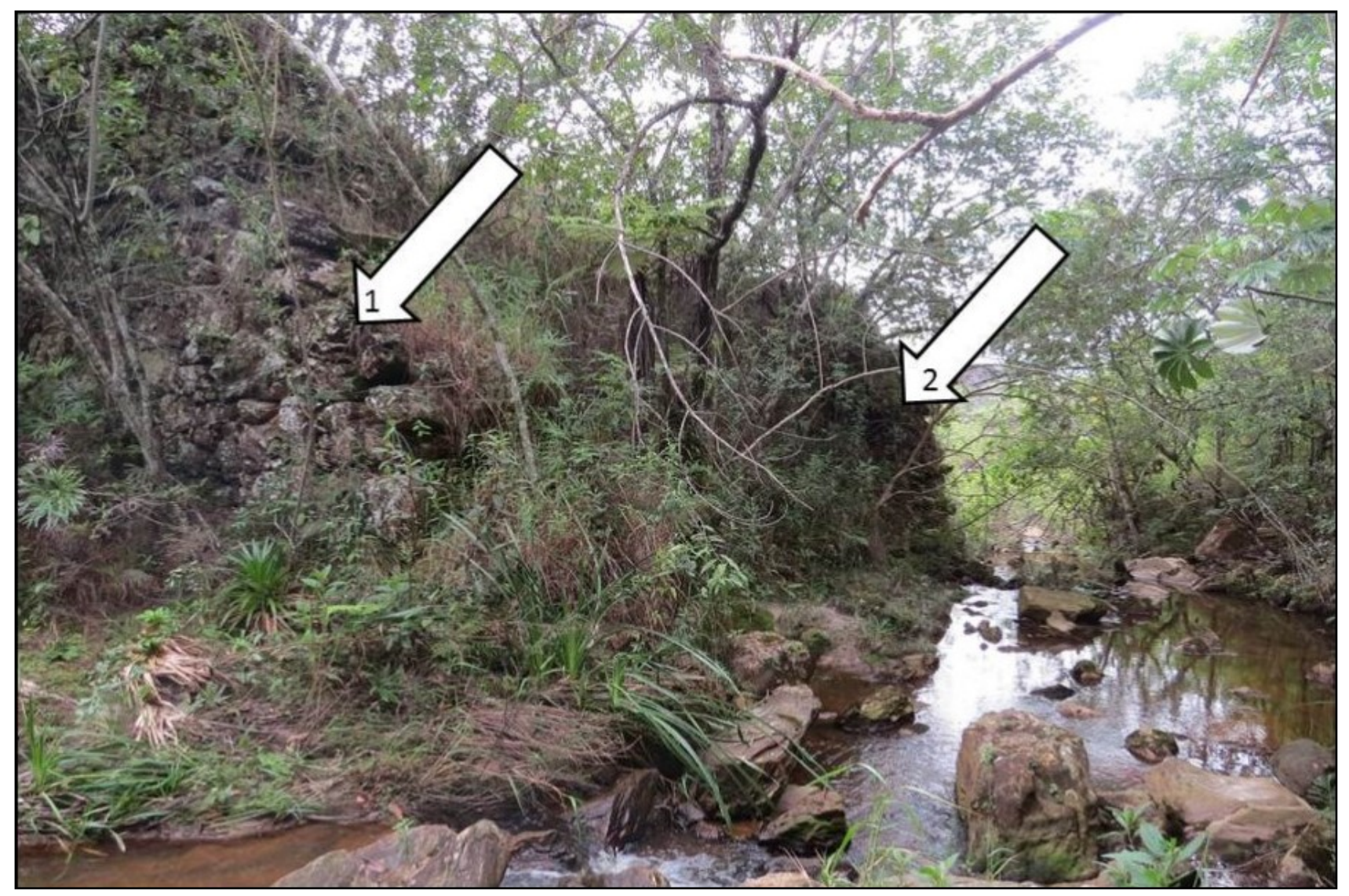

Figura 3 - Resquícios da barragem inicial do "Canal dos Ingleses". Setas indicando os rompimentos do duplo dique pela força das águas em distintos períodos chuvosos.

Fonte - Ulisses Passarelli, 2016 / SMCT/SJDR. 


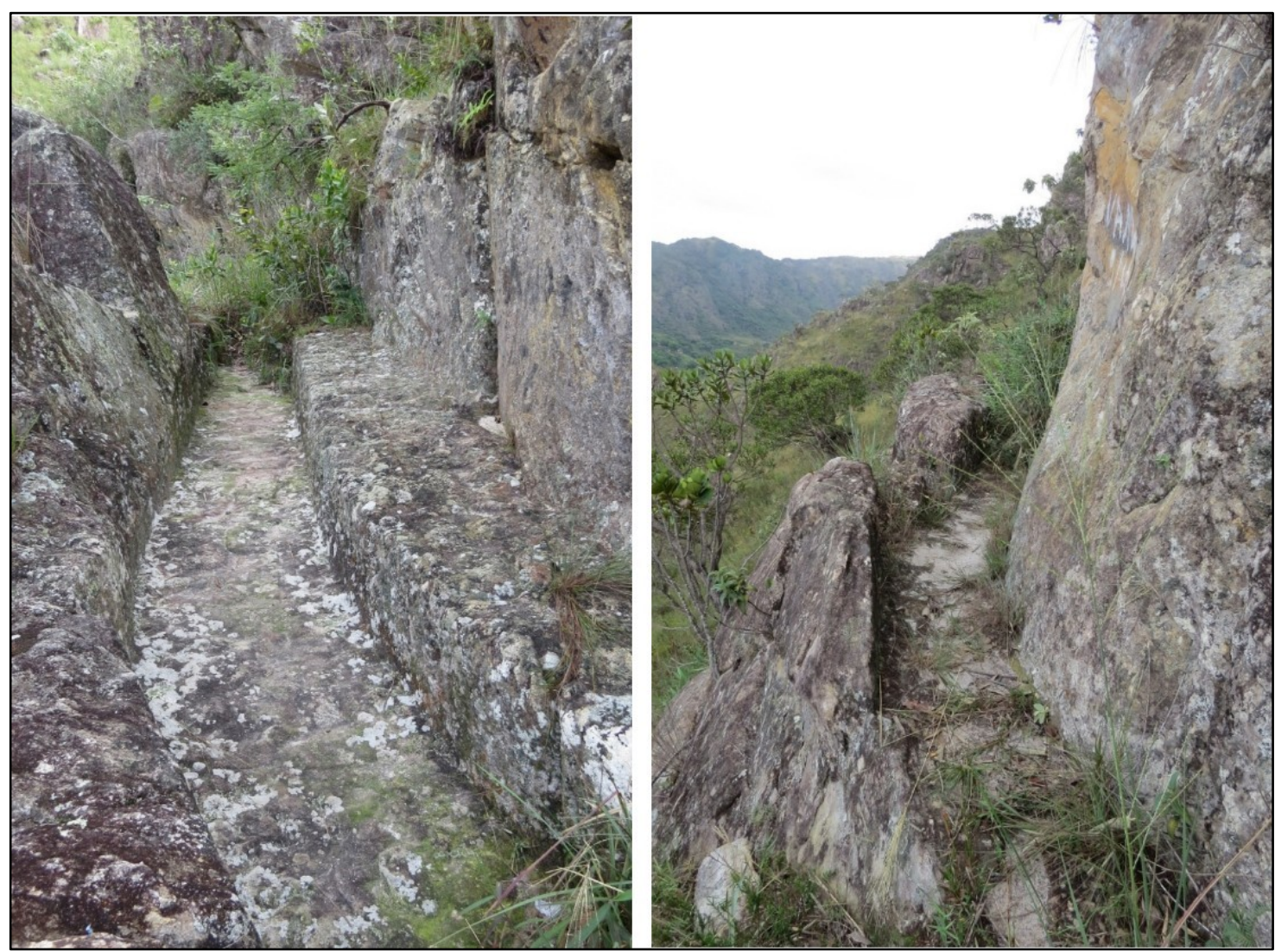

Figura 4 - Canal do Ingleses, escavado sobre a rocha quartzítica. Fonte - Luciano Oliveira, 2016.

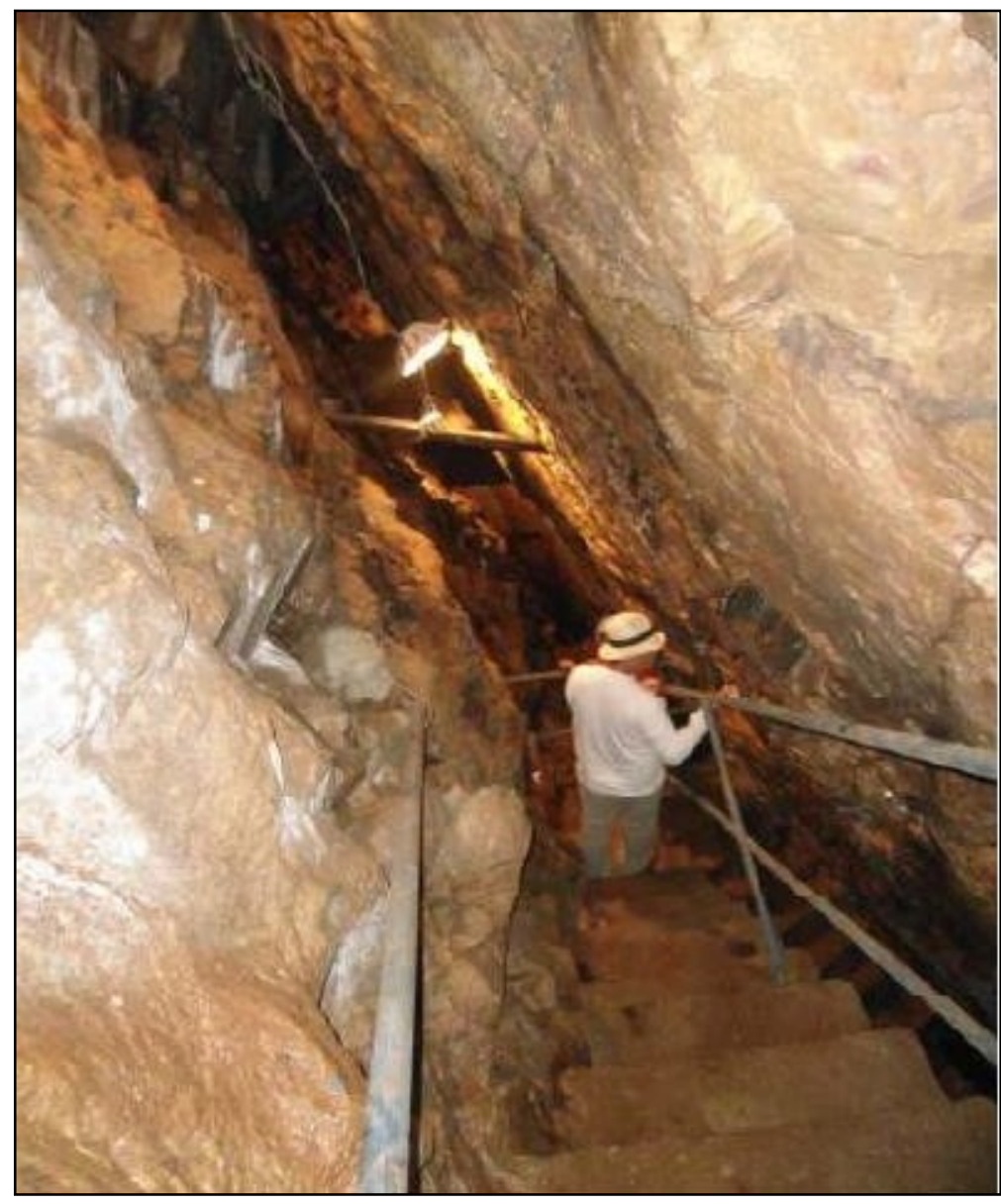

Figura 5 - Bêta típica da Serra do Lenheiro, conservada como atrativo turístico. Fonte - Ferreira et al., (2014). 


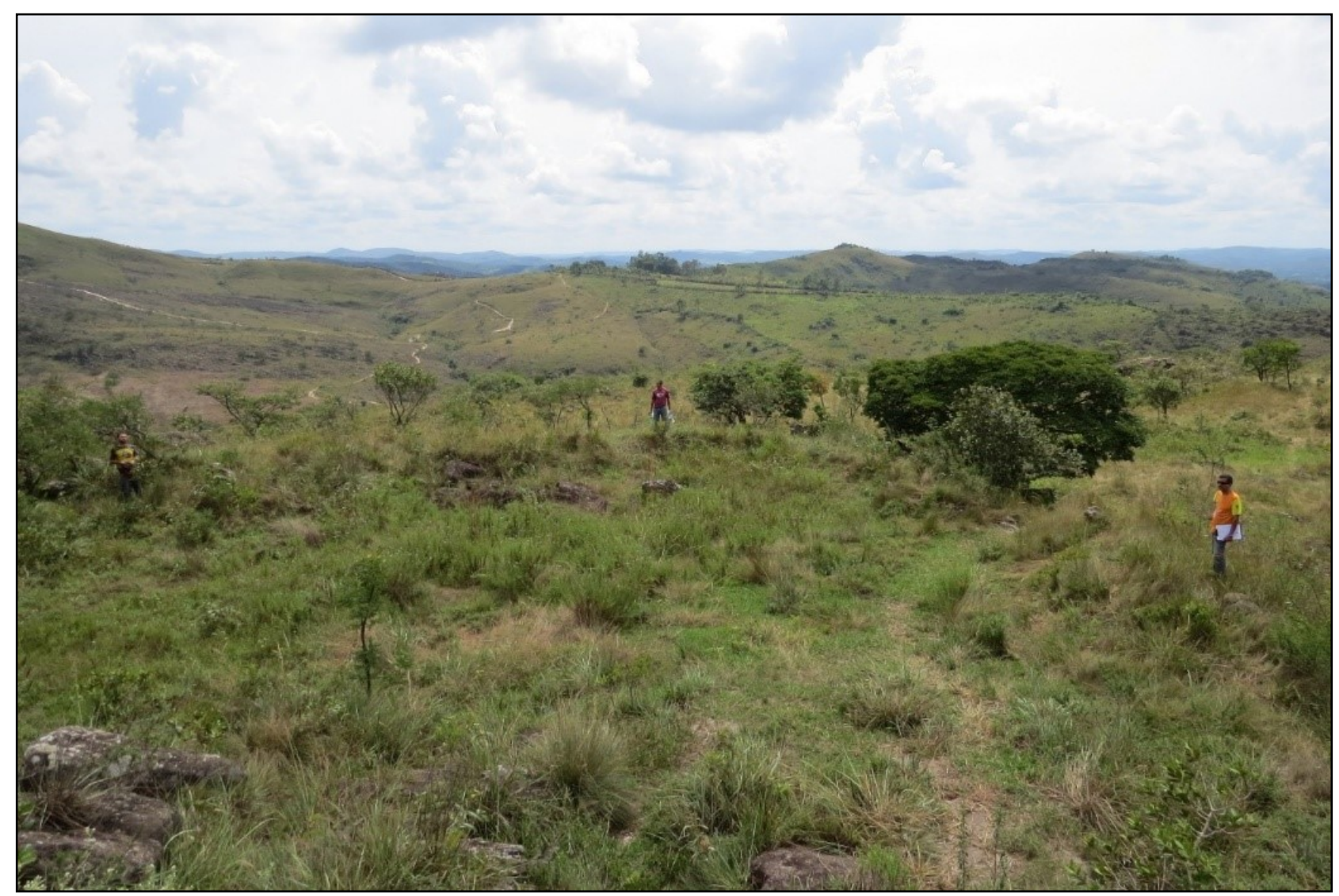

Figura 6 - Resquício de barragem do tipo "Mundéu” (forma parabólica do terreno, no meio da foto, com uma pessoa situada na sua borda jusante).

Fonte - Luciano Oliveira, 2016.

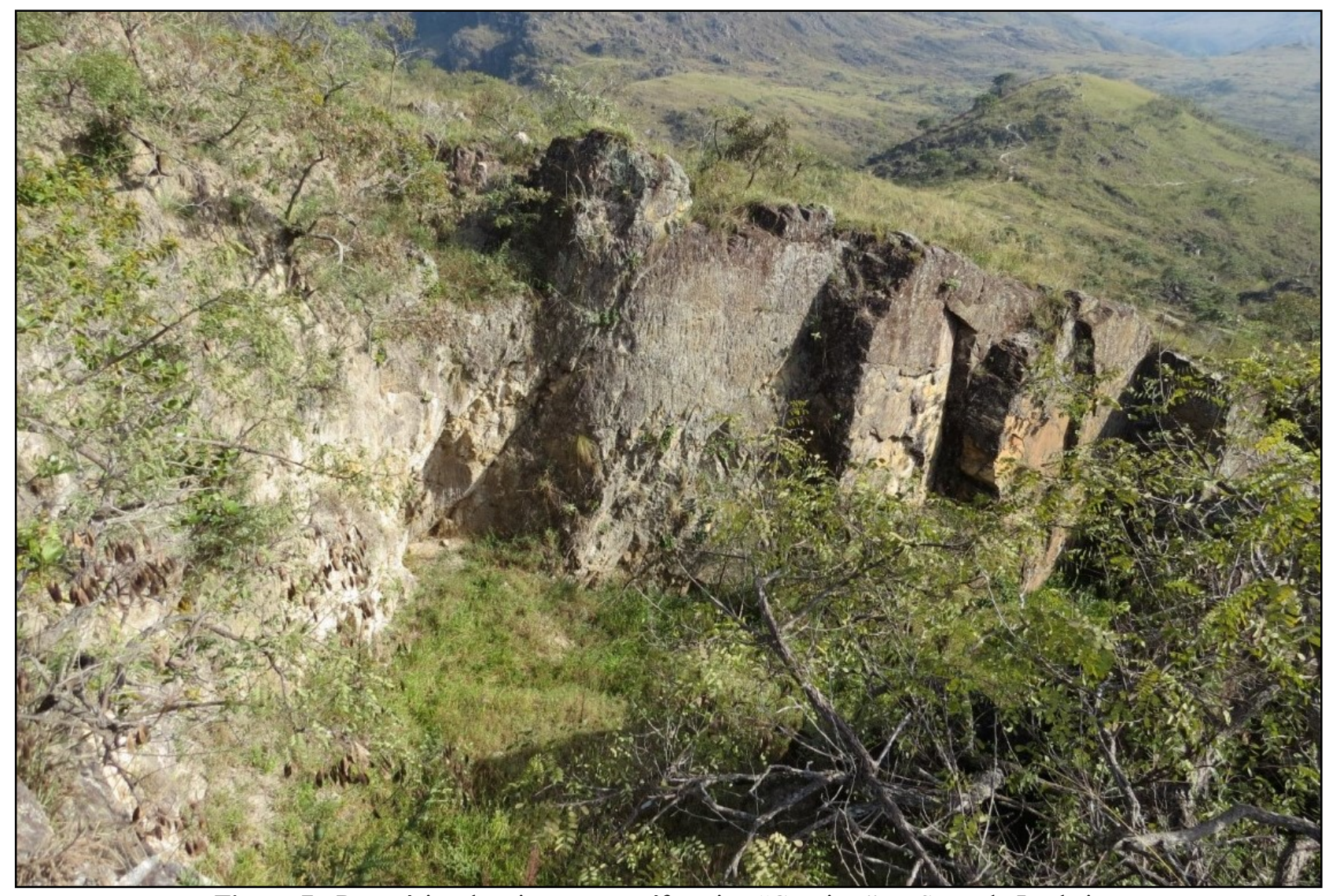

Figura 7 - Resquícios da mineração aurífera tipo "Grupiara” na Serra do Lenheiro.

Fonte - Ulisses Passarelli, 2017. 
Assim, a Serra do Lenheiro possui os significados necessários para ser considerada um patrimônio natural e mineiro, pois, a cidade de São João del-Rei e a região da bacia hidrográfica do Rio das Mortes têm sua história colonial fortemente ligada à prática da mineração.

\section{CONSIDERAÇÕES FINAIS}

Os elementos conceituais apresentados, associados a registros fotográficos de resquícios históricos da mineração, possibilitaram construir um cenário patrimonial mineiro de significativa importância local e regional, trazendo, à luz das reflexões e registros bibliográficos internacionais, uma questão ainda pouco explorada pela comunidade geocientífica brasileira no âmbito da geoconservação e do geopatrimônio. Conforme apontam estudos internacionais em estágios mais avançados, citados neste trabalho, a mineração e os recursos naturais de uma dada região, em determinados momentos históricos, foram ou ainda são determinantes na construção cultural de um povo. Nesse sentido, a investigação de detalhes laborais, de estruturas, construções, técnicas, formas utilizadas na mineração durante esses momentos históricos ajudam a consolidar importantes marcos identitários coletivos. Os desdobramentos deste trabalho serão os de estudar os resquícios míneropatrimoniais apresentados, de acordo com preceitos metodológicos sugeridos na literatura consultada, para que se possa produzir um diagnóstico do cenário apresentado e suas possibilidades e limitações como atrativo geoturístico.

\section{AGRADECIMENTOS}

Os presentes autores agradecem os autores das fotos utilizadas neste trabalho, bem como agradecem a Secretaria Municipal de Cultura e Turismo de São João del-Rei, pela gentileza e cessão das mesmas.

\section{REFERÊNCIAS}

BRILHA, J. B. Patrimônio Geológico e Geoconservação: a conservação da natureza na sua vertente geológica. Braga: Palimage, 2005. 190p.

DEL CAMPO, E. A.; SANZ, C. M.; RODRÍGUEZ, A. S.; GIL, D. P. de L.; DOMINGO, A. G. Guía metodológica para la integración del Patrimonio Minero en la evaluación del impacto ambiental. Madrid: Instituto Geológico y Minero de España, 2012. 40p.

DIAS, L. C. Conflitos e possibilidade entre a atividade minerária e geoconservação na área do Geoparque Costões e Lagunas - RJ. 2015. 152 f. Dissertação (Mestrado em Geologia) - Instituto de Geociências e Ciências Exatas, Universidade Estadual Paulista, Rio Claro, 2015.

ESCHWEGE, W. L. Pluto brasiliensis. Brasília: Senado Federal, 2011. 722p. 
EUROMINES. European Association of Mining Industries, Metal Ores \& Industrial Mineral. 2017. Disponível em: <www.euromines.org>. Acesso em: 13 nov. 2017.

FERNÁNDEZ, G.; RAMOS, A.; VALENZUELA, S.; RICCI, S. Geodiversidad, patrimonio minero y geoturismo: propuesta de parque geominero en Argentina. Turismo y Sociedad, v. 17, p. 17-27. 2015.

FERREIRA, A. C. Serra do Lenheiro, um conjunto de geossítios e suas inter-relações constituindo um relevante geoheritage. 2017. 337 f. Dissertação (Mestrado em Geografia), Universidade Federal de São João del-Rei, São João del-Rei, 2017.

FERREIRA, A.; ROCHA, L.; FIGUEIREDO, M.; SANTOS, P.; ANDRADE, R. Proposta de criação de um roteiro geoturístico nas cavidades naturais e artificiais do município de São João Del-Rei MG. Tourism and Hospitality International Journal, v. 2, n. 1, p. 174-193, 2014.

GAIO SOBRINHO, A. Visita à colonial cidade de São João Del Rei. São João del-Rei: FUNREI, 2001. 128p.

GARCÍA-CORTÉS, Á. Contextos geológicos españoles: una aproximación al patrimonio geológico español de relevancia internacional. Madrid: Instituto Geológico y Minero de España, 2008. 235p.

GUIMARÃES, G. B.; LICCARDO, A.; PIEKARZ, G. F. A. valorização cultural do patrimônio geológico-mineiro do Paraná. Boletim Paranaense de Geociências, Curitiba, v. 70, p. 41-52, 2013.

LICCARDO, A.; BARBOSA, T. A.; HORNES, K. L. Diamante de Tobalgi no Paraná: Patrimônio Geológico-Mineiro e Cultural. Anuário do Instituto de Geociências, Rio de Janeiro, v. 35, n. 1, p. 142-151, 2012.

LOMBARD, L. A mineração nos municípios de São João del Rey, Tiradentes e Prados. "OURO" no Estado de Minas Geraes. Revista Industrial de Minas Geraes, n. 10, p. 243-246, 1894b.

LOMBARD, L. Note sur les explotations des mines d'or anciennes aux environs de São João del Rey, Tiradentes et Prados. Revista Industrial de Minas Geraes, n. 6, p. 133-135, 1894a.

MARCHAN, C.; SÁNCHEZ, A. Consideraciones sobre el Patrimonio Minero desde la Perspectiva de um Servicio Geológico Nacional. Boletim Paranaense de Geociências, Curitiba, v. 70, p. 77-86, 2013.

MORANDI, T. A.; SCHIAVONI, F. L.; MIRANDA, Z. C. Análises de processos criativos influenciados pelo espaço e memória. R. Inter. Interdisc. Art \& Sensorium, Dossiê SIAUS, v. 5, n. 1, p. 55-68, 2018.

NASCIMENTO, M. A. L.; ROCHA, A. J. D.; NOLASCO, M. C. Patrimônio geológico e mineiro no Nordeste do Brasil. Boletim Paranaense de Geociências, Curitiba, v. 70, p. 103-119, 2013.

PEARSON, M.; McGOWAN, B. Mining heritage places assessment manual. Camberra: Australian Council of National Trusts and Australian Heritage Commission, 2000. 212p.

PUCHE RIART, O. La Conservación del Patrimonio Geológico y Minero. In: Instituto Geológico y Minero de España. Ciento cincuenta años (1849-1999). Estudio e investigación en Ciencias de la Tierra. Madrid: IGME, p. 73-101. 2000. Disponível em: $<$ http://oa.upm.es/10202/1/50a\%C3\%B1os.pdf>. Acesso em: 05 nov. 2018. 
RIBEIRO, A.; ÁVILA, C. A.; VALENÇA, J. G.; PACIULLO, F. V. P.; TROUW, R. A. J. Geologia da Folha de São João Del Rei. In: PEDROSA-SOARES, A. C. et al. (Ed.). Projeto Sul Minas, Etapa I: Geologia e Recursos Minerais do Sudeste Mineiro. Belo Horizonte: Companhia Mineradora de Minas Gerais, p. 521-622, 2003.

SANTANA TALAVERA, A. Patrimonios culturales y turistas: Unos leen lo que otros miran. PASOS. Revista de Turismo y Patrimonio Cultural, v. 1, n. 1, p. 1-12, 2003.

TICCIH (The International Committee for the Conservations of the Industrial Heritage). Carta de Nigzny Tagil sobre Patrimônio Industrial. 2003. Disponível em: <http://ticcih.org/wpcontent/uploads/2013/04/NTagilPortuguese.pdf>. Acesso em: 02 nov. 2018.

VALERIANO, C. M. Geologia Estrutural e Estratigrafia do Grupo São João del Rei, na Região de São João del Rei, MG. 1985. 98 f. Dissertação (Mestrado em Geologia) - Instituto de Geociências, Universidade Federal do Rio de Janeiro, Rio de Janeiro, 1985.

Trabalho enviado em 18/11/2018

Trabalho aceito em 18/12/2018 